\title{
An Experimental Investigation of the Impact of Specimen Preparation and Curing Conditions on Cement-Treated Material Strength (Deep Mixing Method)
}

\author{
Ahdyeh MOSADEGH ${ }^{\mathrm{a}}$, Fabien SZYMKIEWICZ ${ }^{\mathrm{b}}$, Hamid NIKRAZ \\ ${ }^{a}$ PhD Candidate of Civil Engineering, Curtin University, Perth, Australia \\ ${ }^{b}$ Researcher at Université Paris Est-IFSTTAR, Paris, France \\ ${ }^{c}$ Professor of Civil Engineering, Curtin University, Perth, Australia
}

Corresponding author at: Department of Civil Engineering, School of Civil and Mechanical Engineering, Curtin University-Bentley Campus, Perth, Australia Tel.: +61-452 502 080; Fax: +61-8-9266-2681

E-mail address: ahdyeh.mosadegh@postgrad.curtin.edu.au 


\section{An Experimental Investigation of the Impact of Specimen Preparation and Curing Conditions on Cement-Treated Material Strength (Deep Mixing Method)}

In recent decades the use of Deep Mixing Method (DMM) has developed considerably and its applications are increasing continuously. Although during the past few decades various DMM techniques and methods have been introduced in different projects, there are many changing parameters which makes it necessary to evaluate the impact of each condition in any specific project. The present laboratory study has been carried out to determine the impact of mixer type and curing time and conditions on soil stabilised with cement as used in soil mixing methods. Three different types of soil have been used in this research. Unconfined Compression Strength (UCS) and Secant Modulus $\left(\mathrm{E}_{50}\right)$ were chosen to assess the impact of various parameters on soil improvement in terms of strength. Results of UCS tests after a 28-day curing period indicate that type of mixing method has a slight impact on the strength of all types of cement treated soil. It is also concluded that different curing conditions and suction using various salt solutions have a significant impact on the strength of stabilised soil.

KEY WORDS: soil mixing, sand, cement, strength, curing, deep mixing 


\section{Introduction}

Over the past 40 years, Deep Mixing Method (DMM) has seen a continuous growth and has been an economical and ecological alternative to improve soil properties for engineering infrastructures constructions. Soil mixing methods can be subdivided into four general types including deep, shallow, wet and dry mixing. Deep Soil Mixing is the mechanical mixing of in situ soil with cement and/or lime as a stabilizing agent which creates soil-treated columns and improves the engineering properties of the ground. In this method, soil treatment is performed to a minimum depth of $3 \mathrm{~m}$. Shallow mixing is another method to improve soft and compressible soil properties. The treatment depth is limited to a few meters and traditionally involves the shallow subgrade stabilization in road constructions. For both deep and shallow mixing methods there are two different mixing methods of wet and dry. The existing soil which has to be improved can be mixed mechanically either with a cement-based slurries (wet method) or dry additives such as cement and lime (dry method) (Massarsch \& Topolnicki, 2005).

In deep mixing which is the method used for this study, shear strength increases by reducing the compressibility of the soil structure which produces a low permeability ground type. This method has usually been applied to improvement of soil in embankments, foundations support (temporary or permanent), bridge and wind turbine foundations, excavation stabilization, secant walls and barriers, slope stabilization, encapsulation and immobilization of pollutants (Indraratna, 1996; Porbaha et al., 1998). The general expectation of using deep mixing method is a significant change to the properties of the soil such as increasing soil strength, change in water content, density, permeability, elastic modulus and limitation of settlement (Bouazza et al., 2006). Many researches were performed to investigate the impact of different parameters on soilcemented strength in deep mixing. The main parameters affecting soil strength investigated by researchers are soil and binder physical and organic properties (Kitazume 
\& Terashi, 2013), curing condition (Hirabayashi et al., 2009; Kitazume \& Terashi, 2013; R. Babasaki et al., 1996) mixing method including mixing time and speed (Kitazume \& Terashi, 2013) mellowing time (Åhnberg, 2009; Marzano et al., 2009), soil compaction ((Åhnberg, 2009; Hirabayashi et al., 2009; Kitazume \& Masaki, 2009) mixing procedure (Kitazume \& Terashi, 2013; F. Szymkiewicz et al., 2012; Yoshizawa H. \& Hosoya Y., 1997) and mixing tools (Åhnberg, 2009; Larsson, 2003; Szymkiewicz 2011).

This paper focuses on the impact of some laboratory factors including mixing methods, curing time, curing condition and relative humidity on the strength of cementtreated material in deep mixing. In order to analyse the reason for mixer impact on soilcement strength, density variation of all mixtures and the relation between secant modulus of all material and unconfined compressive strength were discussed and analysed.

\section{Materials and methods}

This laboratory study has been carried out in order to determine the impact of mixer type, curing conditions on the stabilized soil strength. The unconfined compression strength test on cylindrical samples has been chosen to analyse soil-cement strength. In the following section, materials used in this research are presented. Then, the methods and different curing conditions investigated in this study will be discussed and finally the results of several laboratory tests will be presented followed by discussion and analysis.

Soil and binder: In this section, characteristics of different materials used in this study will be presented. These materials are Fontainebleau sand, kaolinite and cement. It is noted this article is part of a research program took place in a research centre called IFFSTAR in Paris, therefore the material were selected from local resources. The grain size and hydrometry tests were carried out according to French standards, NF P 94-056 and NF P 94-057, respectively and grain size distribution curves are presented in Figures 1 and 2 (AFNOR, 2003a). Fontainebleau sand is a uniform sand consisting of fine and 
rounded particles with an average mean particle size of $\mathrm{D}_{50} \# 0.2$ and Dmax\#0.4 mm. The other soil is kaolinite. The grain size distribution curve of that is presented in Figure 2 and chemical proprieties are presented in Table 1 . The soil has a neutral $\mathrm{pH}$ of $(7.5 \pm 0.5)$. In addition to basic characterization tests, Methylene Blue Adsorption (MBA) test was performed in order to better analyse the mineralogical composition of Kaolinite and the amount of methylene blue adsorbed by a given mass of clay was $M B A=1.25$. For stabilization purposes cement was chosen as a main stabilizer and it is classified as CEM III/C 32.5 NCE PM-ES NF which is the cement mainly used in different infrastructures constructions in civil engineering projects in France.

Sample preparation: In this study three types of cement-treated mixtures including "Fontainebleau sand- cement", "kaolinite-cement" and Fontainebleau sandkaolinite- cement" were used. For the last mixture or sand- kaolinite- cement, the percentage of each soil is 50 percent. Other mixture properties including cement and water content of each mixture are presented in Table 2. It should be noted that deep mixing method is a method that is implemented without compaction. It means that material should be selfcompacting or they should be fluid enough to flow under its own weight. In general water is an essential material in deep mixing and in case of cementitious material, $C / W$ or ratio of cement to water is important. It is also noted that the material's workability limit varies greatly with cement content. The lower the cement to water ratio, the higher the void ratio and the lower strength thus $W$ must be at least equal to liquid limit of the mix. Therefore, it is possible, knowing only the plasticity index of the soil to be treated, to estimate the optimum amount of water to add to the mix, after having previously determined the dosage of cement to be used. To determine the workability evolution of the material, the result of a laboratory research program carried 
out by Szymkiewicz et al was adopted for this study. More detail can be found in (Szymkiewicz 2011; F. Szymkiewicz et al., 2013).

Mixing process: A mixer should be capable of mixing soil and binder uniformly. Two types of mixer, small and grand were chosen to mix the soil and binder as shown in Figure 3.a. The small mixer is a variable speed 5-litre mixer which is used for preparation of mixtures of not very high viscosity (according to EN 196-1). The rotation speed is 230 rpm and machine power is $300 \mathrm{~W}$. The grand mixer is a variable speed 12-litre mixer. This mixer is recommended in NF P 94-093 standards to be used for mixing stabilized soil in France (AFNOR, 1999, 2003b). It has two options of slow and fast mixing while both movements of tank and shaft cutter ensure perfect homogenisation. The slow speed was selected and to achieve a better level of mixing, homogenization was performed manually by operator while mixing. For uniform mixing, first soil was added to the mixer. Then, an appropriate amount of cement was put into the mixer and materials were homogenized and at the end water was added. Grand mixer has the power of $2800 \mathrm{~W}$. Mixing time varies based on type of soil and was selected five minutes for granular soils and 15 minutes for cohesive ones. These mixing times remain unchanged during this study.

Moulding: In the following step the homogenized material was poured in an appropriate mould by filling the mould in three layers through tapping against the surface of a table to remove air bubbles. The lightweight plastic mould of $52 \mathrm{~mm}$ diameter and $110 \mathrm{~mm}$ height was chosen considering the height of specimen was set to be 2.0 to 2.5 times of the diameter, as shown in Figure 4.

Curing conditions: All cement-treated samples were stored in three different curing conditions of humid, submerged and under suction conditions. In humid condition, the specimens in the mould were covered by sealant to prevent the change of water 
content and cured at $\sim 20^{\circ} \mathrm{C}$ over a prescribed curing period (Figure 5.a). In submerged condition the specimens were submerged in a container of tap water after removal from their moulds (Figure 5.b). In suction-controlled condition the removed specimen were put in sealed containers with different salt solutions in order to create different relative humidity (RH) condition (Figure 5.c). The desired relative humidity selected in this research were $0 \%, 29 \%, 55 \%$ and $76 \%$ and salts selected to produce this humidity are listed in Table 3. The suction values that can be achieved in the specimen range from 37 $\mathrm{MPa}$ to $250 \mathrm{MPa}$. The glass desiccators were placed in a room temperature for 14 and 28 days to allow soil specimen to achieve equilibrium condition with respect to suction values at controlled chamber at 20 degrees. Abbreviations cited in Table 4 are presenting type of soils, mixing process, and curing conditions. Each symbol consists of three parts separated by dash line. First part presents material type in which $F S, K$, and $S K$ symbolize Fontainebleau sand, Kaolinite and sand - kaolinite material, respectively. Second part presents type of mixing method in which $G M$ and $S M$ are representing preparation by grand or small mixer. Third part indicates curing condition in which $H, S$ and $C$ are symbol of humid, submerge and crystallised condition. For example, FS-GM-H denotes Fontainebleau sand material prepared by grand mixer and kept under humid condition.

Unconfined Compressive Testing: The stabilized soil specimens are mostly used for the Unconfined Compression (UCS) test to measure some factors affecting strength increase of cement treated materials. In order to conduct the UCS test, all samples were removed from mould and the dimensions and weight were measured to calculate the density of each sample. The vertical load was applied on specimen with the speed of 0.3 $\mathrm{mm} / \mathrm{min}$ and test was performed based on NF EN 13286-41 standard which is a French guideline applicable to determine the compressive strength of mixtures treated with hydraulic binders (AFNOR, 2003b). 


\section{Experimental results}

To study the influence of different parameters, the results of UCS test based on different types of preparation and curing conditions are presented in the following section. The average of unconfined compressive strength (UCS) values of triplicate samples are presented as the final result. All samples are treated with cement (at optimum moisture) and UCS test are carried out at room temperature.

\subsection{Influence of mixing processes}

To assess the impact of mixing conditions, UCS tests were carried out under humid condition at different curing time. Results are presented in Figure.6. The charts compare the average of UCS values on three mixtures of soil-treated prepared by small and grand mixers and are tested after 7, 14, 21 and 28 days curing time. In all three charts (Figure 6.a - 6.c) black and white bars present the UCS average of grand and small mixer, respectively. Results show that the strength of all samples prepared by grand mixer is higher than those prepared by small one at any curing time except for kaolinite-treated at 14 days. Moreover, this result is consistent with the results of other researches showing the importance of mixing procedures (Coull, 1997; Kitazume \& Terashi, 2013; Larsson, 2003; R. Babasaki et al., 1996; Szymkiewicz \& et al., 2011).

\subsection{Impact of curing time}

To assess the impact of curing time, the UCS of all samples (excluding those cured under suction) prepared by two mixers at different curing times of 7, 14, 21 and 28 days are measured and results are shown in Figure 7. For sandy soil (Figure 7.a) the compressive strength increases from $2000-2500 \mathrm{kPa}$ at 7 days to $4000-5000 \mathrm{kPa}$ at 28 days for all four different curing conditions. For kaolinite and Fontainebleau-sand-kaolinite treated materials there is a significant increase of strength from 600 to $2100 \mathrm{kPa}$ and from 700 to 
$2100 \mathrm{kPa}$, respectively. These results show that curing time has a major impact on strength increase of cement treated material. Results presented here had a good agreement with those presented by other researchers (Åhnberg, 2009; Kido et al., 2009; Kitazume \& Terashi, 2013; Yoshizawa H. \& Hosoya Y., 1997)

\subsection{Impact of relative humidity}

It is recommended to cure samples at $95-100 \%$ relative humidity to have the most appropriate results (Kitazume \& Terashi, 2013). However, it is not always possible to keep relative humidity at $95-100 \%$ for stabilization purposes. In addition, the difference between strength of samples under different curing conditions which will be illustrated in Figure 10 could be due to humidity level of samples. Therefore, it is important to consider the impact of relative humidity on strength variation of soil-treated materials. It is noted the impact of humidity only is investigated on sand-cement samples due to time and cost saving and the results are presented in Figure 8. As mentioned previously, samples were kept under suction control condition and were put in sealed containers with different salt solutions to create various relative humidity. It can be seen that for both groups, 14 and 28-days, the higher relative humidity is, the higher the strength is except for samples kept under $0 \%$ relative humidity. For all other samples reducing relative humidity leads to a decrease in material strength. To assess the efficiency of salts in inducing suction, the density of sand-treated mixture was calculated and results of 28days sand treated samples are plotted in Figure 9. The graph shows that density increases with increasing relative humidity confirming all salts had reasonable impact on reducing humidity and creating suction in samples. This result is also consistent with UCS results presented in Figure 8.

\subsection{Impact of immersion}


To consider the impact of immersion on soil-treated strength, the results of UCS test after submerging specimens are presented in Figure 10. Darker bar charts present soil strength after immersion for both mixer groups. It can be seen that immersion causes a decrease in UCS compared to humid condition apart from sand treated material at 21 and 28 days prepared by grand mixer. For all other samples prepared by small mixer the strength of submerged soil is lower than those kept in humid conditions. Similar results were obtained by other researchers (Yoshizawa H. \& Hosoya Y., 1997).

\section{Analysis and discussion}

In the previous section, it was concluded that the strength of samples changes with type of mixer. To assess the exact effect of mixers on soil strength, the $N$ value was determined and defined as below:

$$
\mathrm{N}=\mathrm{R}_{\mathrm{c}-\mathrm{GM}} / \mathrm{R}_{\mathrm{c}-\mathrm{SM}}
$$

In which $R_{C-G M}$ is the UCS strength of mixtures achieved by grand mixer and $R_{C \text { - }}$ $S M$ is the UCS strength of samples prepared by small mixer and $N$ is calculated based on equation 1 and results are presented in the Table 5. It should be noted that in Table 5, $N$ is average of all 3 samples prepared at 7, 14, 21 and 28 days. It is clear that $N$ is always bigger than 1 meaning the grand mixer is more efficient than small one in order to increase soil strength. In addition, grand mixer is more efficient for clayey material as $N$ has bigger value when kaolinite quantities increase in the mixture.

To consider the reason for which strength of samples prepared by bigger mixer is higher than those prepared by smaller one, the following section will focus on density variation and determining $E_{50}$ which could be a tool to understand the reason of mixer impact. In addition, $N$ for clayey material is bigger than those for sandy ones. For 
example, for sand and clay treated material $\mathrm{N}$ is 1.11 and 1.21 , respectively which means strength of clayey material prepared by bigger mixer is higher. This can be explained by the fact that the mixers, for a same mixing time, do not deliver the same amount of mixing energy. Therefore, the GM is more appropriate for the clayey soils. In other words, soils mixed with the SM could also reach these strengths, but during longer mixing time.

Density: The density of material prepared at different curing and preparing conditions are investigated and results are illustrated in Figure 11. The Figure 11.a shows that neither time nor curing condition has impact on density change. However, soil density changes with the type of soil (Figure 11.b) and by relative humidity (as shown in Figure 9). It can be seen the average density value for Fontainebleau, kaolinite and sandkaolinite treated material were 2.05, 1.45 and $1.62 \mathrm{gr} / \mathrm{m}^{3}$, respectively. Average density changes with relative humidity as well. For the specimen prepared at $0 \% \mathrm{RH}$ density is $1.9 \mathrm{gr} / \mathrm{cm}^{3}$ and with increasing relative humidity to $100 \%$ density increases to 2.04 $\mathrm{gr} / \mathrm{cm}^{3}$. Therefore, it is difficult to conclude how the mixer type affects the results. It is also important to investigate other factors' impact on soil strength such as energy of mixing or geometry of mixer tool which could affect the soil strength results. The combination of all these factors could be the reason and the study of these factors would be interesting to be assessed in future studies.

Secant Modulus $\mathbf{E}_{50}$ : The secant modulus $\left(E_{50}\right)$ values are obtained from the stress-strain curves and defined as the ratio between the half of maximum deviator stress and the strain corresponding to each stress (Eurosoilstab, 2002). The impact of mixer type on material elasticity change is investigated and results are shown in Figure 12. Vertical axis represents $E_{50}$ or the Young's modulus of elasticity $\left(E_{50}\right)$ and horizontal axis represents the UCS of samples. It is noted circle and triangle markers illustrate small mixer and diamond, asterisk and cross markers denote grand mixers' elasticity. It can be 
seen that mixer type has no significant impact on the sample elasticity variations. As shown in Figure 12, the data points of the plot are spread out across the graph regardless of mixer type. However, type of soil has significant impact on soil elasticity and higher material strength and elasticity modulus are observed for sand material as shown in Figure12. The impact of curing time on material elasticity is investigated and results are shown in Figure 13. It can be seen that both UCS and $\mathrm{E}_{50}$ increase by time and at 28 days curing, the values of $\mathrm{E}_{50}$ are at least two times higher than those cured at 7 days which shows the impact of curing time on increasing $\mathrm{E}_{50}$. It is noted a linear relationship between $\mathrm{E}_{50}$ and the UCS is observed which is shown as dashed lines on both graphs. For example, for clay soil when $\mathrm{q}_{\mathrm{u}}$ is less than $2 \mathrm{MPa}$ the $\mathrm{E}_{50}$ is $800 \mathrm{MPA}$ or $\mathrm{E}_{50}=400 \mathrm{Xqu}$ and for sandy soil when qu is $4 \mathrm{MPa}$ the $\mathrm{E}_{50}$ is $1000 \mathrm{MPa}$ or $\mathrm{E}_{50}=250 \mathrm{Xqu}$. It can be concluded in this study the magnitude of $\mathrm{E}_{50}$ increases with qu and is 125 to 500Xqu depending on type of soil and curing time. These interval values is consistent with those proposed by other researchers in the literature. (Porbaha et al., 2000; Terashi 1977).

\section{Conclusions}

Laboratory study for three types of soil stabilized with cement were conducted to investigate the improvement in compressive strength based on mixing method and curing conditions for application in Deep Soil Mixing Method. Two types of mixer and different curing conditions were studied and results were compared. Based on the test results, specific conclusions can be drawn as follows:

- The strength of all samples prepared with grand mixer is higher than those prepared by small mixer at any curing time. The density of specimens does not change with mixer type which makes it difficult to conclude the main reason for strengths variation by two mixers. This difference might be related to the energy of mixing or the geometry of tools which would be of interest to be furthered. 
- For all samples the strength decreases by submerging samples except for sandy samples which were prepared by grand mixer at 21 and 28 days of curing.

- As it is expected the curing time has a significant effect on the improvement of compressive strength of all cement-treated material.

- The results of UCS test for the specimens kept under different relative humidifies shows that the more humidity increases, the higher the strength is except for sample which was kept under $0 \%$ humidity.

- Results obtained from unconfined compressive strength test are consistent with the results obtained from $\mathrm{E}_{50}$ values and $\mathrm{E}_{50}$ has the similar trend with UCS results. Mixer type has no impact on the sample elasticity variations, while type of soil has a significant impact and higher material strength and elasticity modulus are observed for sand material. Moreover, curing time has an important influence on elasticity variation and for those samples at 28days of curing time $\mathrm{E}_{50}$ is almost two times bigger than those prepared at 7days.

- With increasing $\mathrm{E}_{50}, \mathrm{q}_{\mathrm{u}}$ increases and an approximate linear relationship of 100 $500 \mathrm{q}_{\mathrm{u}}$ was found between $\mathrm{E}_{50}$ and UCS. In addition, the ratio of $\mathrm{E}_{50} / \mathrm{q}_{\mathrm{u}}$ is higher for clayey material than sandy ones.

- It would be interesting to study in further the importance of different factors such as viscosity of liquids, distribution of suspensions and external forces which might affect soil strength in different mixing methods.

\section{References}

AFNOR. (1999). Détermination des références de compactage d'un matériau.

AFNOR. (2003a). Geotechnical investigation and testing - Identification and classification of soil. Part 1: identification and description. France. 
AFNOR. (2003b). Mélanges traités et mélanges non traités aux liants hydrauliques Partie 41: méthode d'essai pour la détermination de la résistance à la compression des mélanges traités aux liants hydrauliques.

Åhnberg, H. H. G. (2009). Influence of laboratory procedures on properties of stabilised soil specimens. Paper presented at the The International Symposium on Deep Mixing and Admixture Stabilization.

Bouazza, A., Haque, A., Kwan, P., \& Chapman, G. (2006). Strength Improvement of Coode Island Sand by the Soil Mixing Method Australian Geomechanics, 41(3).

Coull, M. (1997). The Use of Deep Mixing Methods to Improve Foundations for Port Structures and Their Application to the Dalian Grain Terminal Project University of Canterbury, Australia.

Eurosoilstab. (2002). The Deep Mixing Method: Principle, Design and Construction: Taylor \& Francis.

Hirabayashi, H., Taguchi, H., Tokunaga, S., Shinkawa, N., Fujita, T., Inagawa, H., \& Yasuoka, N. (2009). Laboratory mixing tests on cement slurry preparation, specimen preparation and curing temperature.

Indraratna, B. (1996). Utilization of lime, slag and fly ash for improvement of a colluvial soil in New South Wales, Australia. Geotechnical \& Geological Engineering, 14(3), 169-191. doi:10.1007/BF00452946

Kido, Y., Nishimoto, S., Hayashi, H., \& Hashimoto, H. (2009). Effects of curing temperatures on the strength of cement-treated peat. Proceedings of International Symposium on Deep Mixing and Admixture Stabilization.

Kitazume, \& Masaki. (2009). Influence of specimen preparation and curing conditions on unconfined compression behaviour of cement-treated clay. Proc. of International Symposium on Deep Mixing and Admixture Stabilization.

Kitazume, \& Terashi. (2013). The Deep Mixing Method: Taylor \& Francis.

Larsson, A. (2003). Mixing processes for ground improvement by deep mixing.

Marzano, I., Al-Tabbaa, A., \& Grisolia, M. (2009). Influence of sample preparation on the strength of cement-stabilised clays. Proceedings of Deep Mixing '09, Okinawa.

Massarsch, \& Topolnicki. (2005). Regional Report: European Practice of Soil Mixing Technology. Retrieved from

Porbaha, A., Shibuya, S., \& Kishida, T. (2000). State of the art in deep mixing technology. Part III: geomaterial characterization. Proceedings of the ICEGround Improvement, 4(3), 91-110.

Porbaha, A., Tanaka, H., \& Kobayashi, M. (1998). State of the art in deep mixing technology: part II. Applications. Proceedings of the ICE-Ground Improvement, 2(3), 125-139. 
R. Babasaki, M. T. T. S., Maekawa, A., Kawamura, M., \& Fukazawa, E. (1996). Factors influencing the strength of improved soil. Japanese Geotechnical Society Technical Committee Reports:, 2, 913-918.

Szymkiewicz, \& et al. (2011). Influence des conditions de mélange et de cure sur les caractéristiques de sols traités au ciment par soil mixing.

Szymkiewicz , F. (2011). Évaluation des propriétés mécaniques d'un sol traité au ciment. (PhD thesis), Université Paris-Est, Paris, France.

Szymkiewicz, F., Guimond-Barrett, A., Le Kouby, A., \& Reiffsteck, P. (2012).

Influence of grain size distribution and cement content on the strength and aging of treated sandy soils. European Journal of Environmental and Civil Engineering.

Szymkiewicz, F., Guimond-Barrett, A., Le Kouby, A., \& Reiffsteck, P. (2013). Optimization of strength and homogeneity of deep mixing material by the determination of workability limit and optimum water content. Canadian Geotechnical Journal, 50(10), 1034-1043.

Terashi (1977). Deep mixing method-Brief state-of-the-art. 14th International Conference on Soil Mechanicsand Foundation Engineering.

Yoshizawa H., O. R., \& Hosoya Y., S. M.,

Yamada T.,. (1997). Factor affecting the quality of treated soil during execution of DMM. Ground Improvement Geosystems, 2, 931-937. 
Table 1. Chemical composition of kaolinite

Table 2. Mixtures Properties

Table 3. Salts and relative humidity

Table 4. Scheme of tests and symbols

Table 5. Mixer type effect

Figure 1. Type your title here.

Figure 1. Particle distribution of Fontainebleau sand

Figure 2. Particle distribution of kaolinite

Figure 3. Electric mixers (a) small mixer with flat type binder (b) grand mixer and sharp binder

Figure 4. Different stages of specimen preparation

Figure 5. Different curing conditions (a) humid (b) submerged and (c) crystalized Figure 6. Impact of mixing method on cement treated material (a) Fontainebleau sand

(b) Kaolinite (c) Fontainebleau sand- kaolinite under humid conditions

Figure 8. Influence of relative humidity on sand-cement treated material strength at room temperature

Figure 9. Density versus relative humidity -Sand

Figure 10. Immersion impact on the strength of (a) Fontainebleau sand-cement (b) Kaolinite-cement (c) Sand \& kaolinite-cement material

Figure 11. Change of density with (a) time (b) type of soil and curing conditions Figure 12. E50 versus UCS based on type of soil

Figure13. $E_{50}$ versus UCS changes based on curing time - Fontainebleau sand-treated 
Ahdyeh Mosadegh is a PhD candidate at Curtin University working on soil behaviour, numerical and experimental aspects. Cyclic behaviour of pipe-soil interaction is the main part of her research. She graduated with a master degree in Geotechnical Engineering from Ecole National des Ponts et Chaussées in France 2010. Previously, she finished her first master in Road \& Transportation from University of Tehran, 2007. She has worked over eight years in civil engineering such as design and supervision of different infrastructures, performing research projects in Iran and France. Currently, she is doing a doctoral research under supervision of Professor Hamid Nikraz in Civil Engineering School of Curtin University. Her research interests are soil stabilization, Finite Element analysis focusing on buried pipe and soil deep mixing stabilizations.

Hamid Nikraz is a professor at the Department of Civil Engineering, School of Engineering, Curtin University, Australia. Prior to his academic career, he had many years of experience working in industry in the Middle East, Europe and Australia. He has provided numerous consultancy services in his field to over 200 organizations nationally and internationally. He obtained his $\mathrm{PhD}$ at Curtin University of Technology in 1989. Dr Nikraz is a fellow member of the Institution of Engineers Australia with over 400 publications in various journals, books and conference proceedings. Professor Nikraz has initiated research works in the area of Geopolymers, Concrete, Soil Stabilization and Pavement Engineering. Professor Nikraz is also the reviewer of many national and international journals. 
Table 1. Chemical composition of kaolinite

\begin{tabular}{|c|c|}
\hline Chemical component & Percentage of component (\%) \\
\hline $\mathrm{Al}_{2} \mathrm{O}_{3}$ & 38.6 \\
\hline $\mathrm{SiO}_{2}$ & 46.1 \\
\hline $\mathrm{Fe}_{2} \mathrm{O}_{3}$ & 0.5 \\
\hline $\mathrm{TiO}_{2}$ & 0.7 \\
\hline $\mathrm{K}_{2} \mathrm{O}$ & 0.01 \\
\hline $\mathrm{Na}_{2} \mathrm{O}$ & 0.2 \\
\hline $\mathrm{CaO}$ & 0.01 \\
\hline
\end{tabular}

Table 2. Mixtures Properties

\begin{tabular}{|c|c|c|c|}
\hline Soil Type & $\begin{array}{c}\text { Cement } \\
(\mathrm{kg} / \mathrm{m} 3)\end{array}$ & W (\%) & C/W \\
\hline Fontainebleau sand & 265 & 19 & 0.73 \\
\hline kaolinite ( Clay) & 400 & 120 & 0.21 \\
\hline $\begin{array}{c}\text { Fontainebleau -kaolinite } \\
(50-50)\end{array}$ & 210 & 65 & 0.2 \\
\hline
\end{tabular}

Table3. Salts and relative humidity

\begin{tabular}{|c|c|}
\hline Chemical & Relative humidity \\
\hline Silica gel & 0 \\
\hline $\mathrm{CaCl}_{2}, 2 \mathrm{H}_{2} \mathrm{O}$ & 29 \\
\hline $\mathrm{Mg}\left(\mathrm{NO}_{3}\right), 6 \mathrm{H}_{2} \mathrm{O}$ & 55 \\
\hline $\mathrm{NaCl}$ & 76 \\
\hline
\end{tabular}


Table4. Scheme of tests and symbols

\begin{tabular}{|c|c|c|c|c|c|c|c|c|c|}
\hline Soil type & $\begin{array}{c}\text { Mixing } \\
\text { conditions }\end{array}$ & Curing conditions & Symbol & Soil type & $\begin{array}{c}\text { Curing } \\
\text { conditions }\end{array}$ & Symbol & Soil type & $\begin{array}{c}\text { Curing } \\
\text { conditions }\end{array}$ & Symbol \\
\hline \multirow{6}{*}{$\begin{array}{l}\text { Fontainebleau } \\
\text { sand }\end{array}$} & \multirow{3}{*}{ Grand mixer } & Humid & FS-GM-H & \multirow{6}{*}{ kaolinite } & Humid & K-GM-H & \multirow{6}{*}{$\begin{array}{l}\text { Fontaine } \\
\text { bleau } \\
\text { sand- } \\
\text { kaolinite }\end{array}$} & Humid & SK-GM-H \\
\hline & & Submerged & FS-GM-S & & Submerged & K-GM-S & & - & - \\
\hline & & Crystallised & FS-GM-C & & - & - & & - & - \\
\hline & \multirow{3}{*}{ Small Mixer } & Humid & FS-SM-H & & Humid & K-SM-H & & Humid & SK-SM-H \\
\hline & & Submerged & FS-SM-S & & Submerged & K-SM-S & & Submerged & SK-SM-S \\
\hline & & Crystallised & FS-SM-C & & - & - & & - & - \\
\hline
\end{tabular}


Table 5. Mixer type effect

\begin{tabular}{|c|c|c|}
\hline Soil & Curing condition & $\mathrm{N}^{*}$ \\
\hline \multirow{3}{*}{ Fontainebleau sand } & FS-GM-H & \multirow{3}{*}{1.11} \\
\hline & FS-SM-H & \\
\hline & $\mathrm{N}=\mathrm{R}_{\mathrm{C}-\mathrm{GM}} / \mathrm{R}_{\mathrm{C}-\mathrm{SM}}$ & \\
\hline \multirow{3}{*}{ Kaolinite } & $\mathrm{K}-\mathrm{GM}-\mathrm{H}$ & \multirow{3}{*}{1.15} \\
\hline & $\mathrm{K}-\mathrm{SM}-\mathrm{H}$ & \\
\hline & $\mathrm{N}=\mathrm{R}_{\mathrm{c}-\mathrm{GM}} / \mathrm{R}_{\mathrm{c}-\mathrm{SM}}$ & \\
\hline \multirow{3}{*}{ Fontainebleau sand- kaolinite } & S-K-GM-H & \multirow{3}{*}{1.21} \\
\hline & S-K -SM-H & \\
\hline & $\mathrm{N}=\mathrm{R}_{\mathrm{C}-\mathrm{GM}} / \mathrm{R}_{\mathrm{C}-\mathrm{SM}}$ & \\
\hline
\end{tabular}

